\title{
A Study of the Factors Influencing Inflationary Pressure in the Libyan Economy
}

\author{
Aboagila Otman Ahmed Alkoum ${ }^{1}$, Syed Omar Syed Agil ${ }^{2}$ \\ ${ }^{1}$ Department of economics, Tun Abdul Razak, Malaysia \\ ${ }^{2}$ Department of management, Tun Abdul Razak, Malaysia
}

\begin{abstract}
This paper examines the key determinants of inflation in the Libyan economy using time series data from 1980 to 2011 by applying the ARDL approach. Taking into account the special characteristics of Libya's economy and by considering recent empirical studies in the context of inflation, dynamic macroeconomic model has been constructed which emphasis the effects of money supply, real income, expected inflation, imported inflation, exchange rate, and output gap factors along with dummy variables presenting the structural changes in the Libyan economy during the period of study.
\end{abstract}

Keywords: ARDL model, endogenous structural breaks, inflation.

\section{Introduction}

Inflation is defined as a sustained or continuous rise in the general price level or, alternatively, as a sustained or continuous fall in the value of money (Makinen, 2003). Two things should be noted about this definition .First, inflation refers to the movement in the general level of prices. It does not refer to changes in one price relative to other prices. Second, the rise in the price level must be somewhat substantial and continue over a period longer than a day, week, or month.

Inflation is mostly measured using index numbers such as gross domestic product (GDP) deflator, which indicates to the index of the average price of the goods and services produced in the economy (Parkin, 2000), and wholesale price index (WPI), which measures price changes in the economy at wholesale level (Gupta, 2008), as well as consumer price index, which measures the change in the cost of purchasing a fixed market basket of goods and services representing average consumption patterns during some base period (Moulton, 1996).

During the 1970s and early 1980s, Libya experienced drastic increases in oil revenues. As a result of the developing nature of its economy, and the limited availability of other endogenous resources other than oil and gas, the Libyan economy experienced a rapid increase in almost all macroeconomic variables, especially, the general price level. Table 1 shows the movements of consumer price index and gross domestic product deflator in Libyan economy during period from 1980 to 2011. It indicates that the general rate of inflation in the Libyan economy measured by gross domestic product deflator moved in the range of -24.093 percent in 2009 to 36.786 percent in 2002 , with the period average of 8.38 percent. In contrast, consumer price index ranged from 9.863 percent in 2002 to 13.806 percent in 1982 with the period average of 5 percent.

An analysis of the historical record of annual data of consumer price index and gross domestic product deflator indicates that the inflation is still a serious problem in Libya threatening living standards and economic growth. Specifically, it pushes some people under the poverty line. For instance, in 2002-2003 an estimated 13\% of the population lived below the absolute poverty line with an income of less than LD418 per month (WB, 2006). In addition to that high inflation rates negatively affect on growth rates in Libya by reducing the expectations of returns on investment which lead reduced FDI inflows. According to Krim (2009), Libyan inflation rate is unstable and fluctuates widely which acts as a barrier to FDI inflow. Therefore, there is a need to determine the main factors behind increasing the general price level in order to minimize the adverse its effects on economic growth and development in the local economy.

Table 1: Consumer Price Index and Gross Domestic Deflator in Libya (1980-2011)

\begin{tabular}{|c|c|c|c|c|}
\hline Year & consumer price index & $\begin{array}{c}\text { growth rate of consumer } \\
\text { price index }\end{array}$ & $\begin{array}{c}\text { gross domestic product } \\
\text { deflator }\end{array}$ & growth rate of \\
product deflator
\end{tabular}


A Study of the Factors Influencing Inflationary Pressure in the Libyan Economy

\begin{tabular}{|c|c|c|c|c|}
\hline 1988 & 64.789 & 3.130 & 25.466 & 0.644 \\
\hline 1989 & 67.682 & 4.465 & 26.396 & 3.651 \\
\hline 1990 & 68.170 & 0.677 & 27.704 & 4.955 \\
\hline 1991 & 76.146 & 11.705 & 26.235 & -5.302 \\
\hline 1992 & 83.341 & 9.449 & 28.617 & 9.079 \\
\hline 1993 & 89.571 & 7.475 & 29.184 & 1.981 \\
\hline 1994 & 99.129 & 10.671 & 30.582 & 4.790 \\
\hline 1995 & 107.399 & 8.343 & 37.530 & 22.719 \\
\hline 1996 & 111.690 & 3.995 & 41.732 & 11.196 \\
\hline 1997 & 115.695 & 3.586 & 45.418 & 8.832 \\
\hline 1998 & 119.999 & 3.720 & 45.826 & 0.898 \\
\hline 1999 & 123.087 & 2.573 & 54.378 & 18.661 \\
\hline 2000 & 119.509 & -2.907 & 61.596 & 13.273 \\
\hline 2001 & 108.945 & -8.839 & 67.800 & 10.072 \\
\hline 2002 & 98.200 & -9.863 & 92.741 & 36.786 \\
\hline 2003 & 96.178 & -2.059 & 100.00 & 7.827 \\
\hline 2004 & 97.182 & 1.044 & 122.648 & 22.648 \\
\hline 2005 & 100.00 & 2.890 & 152.186 & 24.083 \\
\hline 2006 & 101.536 & 1.536 & 173.504 & 14.007 \\
\hline 2007 & 107.728 & 6.098 & 195.194 & 12.501 \\
\hline 2008 & 118.932 & 10.400 & 245.572 & 25.809 \\
\hline 2009 & 122.293 & 2.826 & 186.404 & -24.093 \\
\hline 2010 & 127.796 & 4.500 & 196.446 & 5.387 \\
\hline 2011 & 139.384 & 9.068 & 241.453 & 22.911 \\
\hline
\end{tabular}

Source: International Monetary Fund, yearbooks, 2005.2008, and 2011

\section{Empirical Survey on Causes of Inflation}

In this section an attempt is made to survey the vast empirical literature on the determinants of inflation in variety countries, paying special attention to the ones conducted on developing economies, including countries from the Arabic region, in order for proper decision making in choosing explanatory variables that are believed to have contributed to high inflation rates in the Libyan economy.

Alomar (2007) examined the main determinants of inflation in Kuwait during the period 1972 to 2004. The researcher used three independent variables namely money supply, real gross domestic product and imported inflation. The study was estimated by using Granger causality test which indicated that domestic inflation is influenced mainly by the development of domestic liquidity which overwhelmed the theoretically expected effect of imported inflation. According to the researcher, these results might be caused by two main factors; the first is the economic and political developments during the period of study, and the second is the difference in constructing each measure of inflation. These factors might be responsible for distorting the expected relationship between domestic and imported inflation.

Barnichon and Peiris (2007) explored the relationship between inflation, the output gap, and real money gap for a sample covering countries of Sub-Saharan namely Botswana, Niger, Cameroon, Nigeria ,Cote d'Ivoire, Rwanda, Ethiopia, Senegal, Ghana, Sierra Leone, Kenya ,Swaziland, Madagascar, Uganda ,Malawi Zambia, Mali, Zimbabwe and Mozambique. To estimate the structural gaps, the researchers used annual data on these countries covering a maximum time span of 1960 to 2003 by employing panel co integration estimation techniques. The results of this study showed that the estimated output gap and money gaps are both economically and statistically significant in accounting for inflation in SSA. In addition, the structural output and real money gaps have a significant predictive power on inflation.

Kandil and Morsy(2009) studied the determinants of inflation in GCC namely Bahrain, Kuwait, Oman, Qatar, Saudi Arabia and the United Arab Emirates during the period from 1970 until 2007, using an empirical model that included potential sources of inflationary pressures, both domestic and external, in the short and long-run. Domestic determinants of inflation included government spending and the money supply, whereas external variables included the nominal effective exchange rate, and a weighted average of price in major trading partners. The results of this study showed that determinants of inflation in the long-run and short-run dynamics vary across GCC countries. In the long-run, the main results revealed that ,firstly, trading partners' inflation is a major determinant of inflation in Bahrain, Kuwait, Saudi Arabia, and the United Arab Emirates, secondly, exchange rate depreciation increases inflation in Bahrain, Oman, Qatar and Saudi Arabia, thirdly, in Bahrain, Oman, and the United Arab Emirates, higher government spending eases capacity constraints and moderates inflation, fourthly, monetary growth increases inflation in Bahrain and the United Arab Emirates. In the short-run, the major results indicated that higher inflation in trading partners increases inflation in Qatar and Saudi Arabia, exchange rate depreciation tends to increase inflation in Bahrain and the United Arab Emirates, higher government spending rises inflation in Bahrain, Kuwait, Oman, and the United Arab Emirates, and 
excess demand, relative to potential is a significant factor for higher inflation in Kuwait, Oman, Qatar, and the United Arab Emirates.

Tang (2010) empirically re-investigated the relationship between money and prices in the Malaysian economy over the period of 1971:01 to 2008:03, employing the co-integration and causality techniques. The estimated results showed that a unidirectional causal relationship run from money supply (M2) to aggregate prices, meaning that the monetarist's view exist in the Malaysian economy. But this relationship between money supply and general level of prices is not stable over the analysis period namely inflation is not always a monetary phenomenon in Malaysia. Therefore, the contractionary monetary policy may not an effective instrument in managing inflationary behavior in Malaysia.

Patnaik (2010) explored the main causes of inflation in India for the period from 1991:2 to 2008:2 by VAR model. The researcher in this study used four variables namely the consumer price index (CPI), which is the measure of inflation, the index of industrial production (IIP) (this represents the volume of demand in the economy), the reserve money (RM) which is a measure of money supply in the economy, and the import index (IMP), which is a measure the external influences on the domestic prices. The main outcomes of this study showed that Indian inflation is mainly demand pull inflation, due to both the money supply and the IIP represent the existing demand in the economy.

Dwyer, Lam, and Gurney (2010) examined the relationship between inflation and input gap in UK during the period from 1981 to 2008 . To the end, the researchers used three different output gap measures; the HM Treasury output gap, the OECD output gap and the HP filter trend output gap. The main findings showed that the output gap has an important role in explaining inflation and suggests that the lagged effect of the large negative output gap will generate significant downward pressure on inflation over the next few years. The estimating also indicated that strong empirical evidence of the influence of import prices on inflation, with a one-off shock to import prices taking around 1 year to fully feed through to inflation.

Oladipo, and Akinbobola (2011) investigated the nature and direction of causality between budget deficit and inflation in Nigeria. This study was with a view to providing empirical evidence on budget deficit operation in stimulating economic growth through inflation in the Nigerian economy .In this study, the authors used secondary data for the period from 1970 until 2005. The results of Granger Causality Test showed that there is no causal relationship from inflation to budget deficit, while the causal relationship from budget deficit to inflation was significant. This implies that a unidirectional causality from budget deficit to inflation exist in Nigeria.

Dizaji (2011) examined determinants of inflation in Iran by using annual data covering the period from 1973 until 2008. He used some econometrics techniques such as unit root test, co integration test. The results of this study indicated that foreign prices, gross domestic product (GDP), exchange rate and the two dummy variables DT80 and DT88 (for capturing the structural break which have been caused respectively by the war with Iraq and the subsequent reconstructions after war) have significantly affected the domestic prices in Iran.

Agayev (2011) explored the determinants of inflation in relatively low inflation period of 1996-2008 in 10 Commonwealth Independent States transition economies. Exchange rate growth, wage increases, money supply growth and inflation inertia were analyzed as determiners of inflation in this study. Results of this study showed that exchange rate appreciation and nominal wage growth do not cause inflation. In contrast, monetary expansion has strong inflationary effects on the general price level in these economies.

Kinda (2011) investigated the sources of inflation in Chad using quarterly data from 1983:Q1 to 2009:Q3. The analysis of this study was based on a single-equation model .The results showed that the main determinants of inflation in Chad are rainfall, foreign prices, exchange rate movements, and public spending. The effects of rainfall shocks and changes in foreign prices on inflation persist during six quarters. Changes in public spending and the nominal exchange rate affect inflation during three and four quarters, respectively.

\subsection{The Theoretical Model}

\section{The Model and Data}

The above empirical studies have tended to suggest that the following variables are mostly responsible for the inflationary process: import prices; interest rates; exchange rates; money supply; output gap; real income; trade deficit; and budget deficit. However, it is not necessary that all variables mentioned in these empirical studies are the real determinants of inflation in the Libyan economy, due mainly to that the Libyan economy is a surplus economy, especially for the balance of trade. Thereby, the equation of inflation in the Libyan economy could be formulated as follows:

$$
\Delta \log P_{t}=a_{0}+a_{1} \Delta \log M_{t}^{s}-a_{2} \Delta \log Y_{t}+a_{3} \Delta \log e_{t}+a_{4} \Delta \log P_{t}^{f}+a_{5} \Delta \log E X_{t}+\mathrm{g}+\mu
$$

Our equation includes domestic prices measured by gross domestic product as the dependent variable, and money supply, real income, expected inflation rate, imported inflation, exchange rate, and output gap as independent variables. 


\subsection{Secondary Data}

The study covers the period from 1980 to 2011. The gross domestic product deflator, consumer price index, and rates of inflation in trading partners were obtained from International Financial Statistics (IFS) of International Monetary Fund. Raw figures on money supply and exchange rate were obtained from Central Bank of Libya, while real income and output gap were calculated by authors. All variables, except exchange rate, were transformed to logarithmic form.

\section{Methodology}

In order to fully grasp the influence tested variables on inflation, this study employs a number of tests, each of which is either necessary for subsequent test or merely sheds further light on the dynamics of inflation.

\subsection{Determining the Stationarity of the Data}

The stationary properties of a time series are scrutinized by carrying out the unit root test to avoid spurious or nonsense regressions. There are a number of tests available for conducting a unit root namely conventional unit root test, which does not take into account structural breaks, and unit root test that takes into account multiple structural breaks. These tests are briefly discussed below.

\subsubsection{Traditional Unit Root Tests}

The most popular and widely used tests in empirical economic studies to examine the stationary of a time series, in absence of a structural break, are the Augmented Dickey-Fuller (ADF) test (Dickey and Fuller, 1979, 1981), and Phillips and Perron (PP) test (1988). These tests are used to investigate the null hypothesis that all the variables have a unit roots, against that they do not, in the level of variables as well as in their first differences.

\subsubsection{Lagrange Multiplier Unit Root Test}

Lee and Strazicich (2003) proposed LM unit root tests with two structural breaks. They considered two models of structural change. "Model A" is known as the "crash" model, and allows for a change in intercept, as well as "Model C" allows for a shift in intercept and change in trend slope. In this study, we consider "Model C" for two breaks test, because it performs better than "Model A" (Sen, 2003; Tang, 2008).

\subsection{The ARDL Approach}

Several statistical techniques were used to estimate determinants of inflation in various countries around the world. In this study, the Auto-regression Distributed Lag (ARDL) Model developed by Pesaran et al. (2001) will be used to examine the long-run relationship between variables which are included in the previous equation, as well as to estimate the short-run and long-run elasticities. The ARDL Model has main advantage over the other common procedures to co integration analysis. This advantage stems from the fact that the other methods focused on the estimation of long-run relationships among $I(1)$ variables, which inevitably involves a certain degree of pre-testing and thus introduces a further degree of uncertainty into the analysis of relationships between levels (DaCosta and Greenidge, 2009; Pesaran et al., 2001).

The ARDL procedure involves two stages. At the first stage the existence of the long- run relation between the variables under investigation is tested by computing the F-statistic for testing the significance of the lagged levels of the variables in the error correction form of the underlying ARDL. The F-test has a nonstandard distribution which depends on (i) whether variables included in the model are I (0) or I (1), (ii) the numbers of regressors, and (iii) whether the model contains an intercept and/or a trend. Two critical values are given by Pesaran et al. (2001) for the co integration test. The lower critical bound assumes all the variables are I (0) meaning that there is no co integration relationship between the examined variables. The upper bound assumes that all the variables are I (1) meaning that there is co-integration among the variables. When the computed F-statistic is greater than the upper bound critical value, then the $\mathrm{H} 0$ is rejected (the variables are co integrated). If the F-statistic is below the lower bound critical value, then the $\mathrm{H} 0$ cannot be rejected (there is no co integration among the variables). When the computed F-statistic falls between the lower and upper bound, then the results are inconclusive. The second stage of the analysis is to estimate the long and short-run elasticities. This estimation is only possible if the long-run relationship is established in the first step.

\subsection{Empirical Results for Traditional Unit Root Tests}

\section{Empirical Results}

The regression results of the ADF and PP unit root tests applied to Libyan data used in this study, with an intercept term and a linear trend, are revealed in Table 2. The findings show that both the ADF and PP tests reject only the null hypothesis of a unit root for output gap (g). This can be seen by comparing the observed 
values of both the $\mathrm{ADF}$ and PP test statistics with the critical values of the test statistics at the $5 \%$ level of significance.

Generally speaking, results from the ADF and PP model are able to reject only 1 out of the 7, representing almost 14 percent of the variables of interest. These results may be biased towards the nonrejection of the unit root test, and the observed unit root behavior, as Perron (1989) suggested, resulting from failure to account for a structural break in the data. Perron (1989) argues that the traditional unit root hypothesis tests may not be reliable in the presence of structural breaks. Hence ignoring structural break(s) in the trend function leads to considerable power reduction of traditional unit root tests. Thereby, applying traditional unit root tests in the absence of structural changes is insufficient, since significant structural breaks are very likely to have occurred in the Libyan economy time series. Thus, we will perform the LM unit root tests with two structural breaks to affirm the order of integration.

Table 2: Traditional Unit Root Tests for stationarity

\begin{tabular}{|c|c|c|c|c|c|}
\hline & $I(0)$ & $I(1)$ & $I(0)$ & $I(1)$ & \\
\hline Variables & $\begin{array}{c}\text { ADF Test } \\
\text { Statistics }\end{array}$ & $\begin{array}{c}\text { ADF Test } \\
\text { Statistics }\end{array}$ & $\begin{array}{l}\text { PP Test } \\
\text { Statistics }\end{array}$ & $\begin{array}{l}\text { PP Test } \\
\text { Statistics }\end{array}$ & Decision \\
\hline Narrow money supply $\left(M^{S}\right)$ & $-0.286395[0]$ & $-6.368664[0]$ & -0.286395 & -6.329874 & $I(1)$ \\
\hline Real income $(Y)$ & $-2.727454[0]$ & $-6.664560[0]$ & -2.729671 & -6.648633 & $I(1)$ \\
\hline Domestic price level $(P)$ & $-1.611620[0]$ & $-5.490258[0]$ & -1.598359 & -5.490512 & $I(1)$ \\
\hline Exchange rate $(E X)$ & $-1.704518[0]$ & $-4.249853[0]$ & -1.836334 & -4.231622 & $I(1)$ \\
\hline Imported inflation $\left(p^{f}\right)$ & $-2.976146[0]$ & $-6.815383[0]$ & -2.809607 & -10.85428 & $I(1)$ \\
\hline Expected inflation $(e)$ & $-1.995309[0]$ & $-5.988912[0]$ & -2.002951 & -6.027707 & $I(1)$ \\
\hline Output gap (g) & $-4.129314[1]$ & & -4.410725 & & $I(0)$ \\
\hline
\end{tabular}

1. All variables in the Table are in log form, with the exception of exchange rate.

2. Critical value of $I(0)$ at the 5 percent level is -3.536601 , whereas critical value of $I(1)$ at the 5 percent level is -3.540328 .

3. The critical values are obtained directly from the empirical results generated by Eviews 5 package.

4. Figures in square brackets besides each $\mathrm{ADF}$ test represent optimum lags, selected automatically using Schwarz Bayesian Criterion (SBC).

5.2 Empirical Results of the Lee and Strazicich Unit Root Model with two Endogenous Structural Breaks.

In this sub-section the two-break minimum LM unit root test is applied to Libyan data to analyze whether the time series is stationary or non-stationary, as well as to determine the major structural breaks that can be used in the regression of the behavioral equation. The regression results for the two-break LM unit root test are reported in Table 3. The LM unit root test indicates that there is additional evidence against the null hypothesis of unit root compared to the result of traditional unit root tests. In other words, while the traditional $\mathrm{ADF}$ and PP unit root tests suggest that $P, E X, p^{f}$, and $e$ are non-stationary, results from the LM unit root test suggest that these time series are trend stationary when the structural break is considered under both the null and alterative hypotheses at un-known time in trend function.

Regarding the stationary series the break dates were consistent with increasing oil prices during the period of the early 1980s ; collapse of oil prices during the mid 1980s until 1990s ; the economic reforms in the early 1990s and the beginning of this century in which the restrictions upon the private sector were alleviated; the United Nation sanctions in the early 1990s; the depreciation of the official exchange rate in 1999; the lifting of sanctions imposed by UN in 2003; and the unification of the exchange rate in 2002.

Table 3: Results of Two-Break Minimum LM Unit Root Test

\begin{tabular}{|c|c|c|c|c|c|}
\hline Variable & T-statistic & & & $\mathrm{k}$ & Result \\
\hline Narrow money supply $\left(M^{S}\right)$ & -4.5024 & 1988 & 2003 & 0 & Unit Root \\
\hline Real income $(\boldsymbol{Y})$ & -4.9039 & 1988 & 2001 & 3 & Unit Root \\
\hline Domestic price level $(P)$ & $-6.0393^{*}$ & 1987 & 1999 & 3 & Stationary \\
\hline 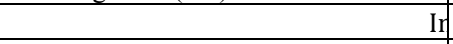 & $-5.7927^{*}$ & 1987 & 1995 & 3 & Stationary \\
\hline Expected inflation $(\boldsymbol{e})$ & $-6.5385^{*}$ & 1989 & 1999 & 4 & Stationary \\
\hline
\end{tabular}

1.The asterisk $*$ denotes statistically significant at 5-percent.

2. The critical values at the five percent significance level are as follows for $P, \mathrm{p}^{\mathrm{f}}$ is $\lambda=(0.2,0.6)=$ -

5.74. for $E X$ is $\lambda=(0.6,0.8)=-5.73$, for e is $\lambda=(0.4,0.6))=-5.67$, and for $g$ is $\lambda=(0.2,0,8)=-5.71$. 
5.3 Empirical Results of the Equation of Inflation in the Libyan Economy Based on the ARDL Model

As has been shown by the unit root tests, especially the results derived from the LM unit root test with two structural breaks. The time series of the behavioral equation in this study is a combination of stationary and non-stationary variables, i.e., the variables consist of a mix of $I(0)$ and $I(1)$ series with structural breaks. For this reason, the ARDL co-integration approach is utilized in this study to analyze the long run relationships and dynamic interactions between the variables in our equation.

Furthermore, the two significant and relevant structural breaks, as well as the trend term and intercept will be included in the behavioral equation (1) as this coincides with the LM unit root test of Lee and Strazicich (2003), which captured two structural breaks in the intercept and trend. Thereby, in line with Pesaran et al. (2001), and without having any prior knowledge about the direction of the relationship among the variables, our ARDL model could be reformulated as follows:

$$
\begin{aligned}
\Delta \log P_{t}=a_{0}+ & \sum_{i}^{n} a_{1 i} \Delta \log M_{t-i}^{s}-\sum_{i}^{n} a_{2 i} \Delta \log Y_{t-i}+\sum_{i}^{n} a_{3 i} \Delta \log e_{t-i}+\sum_{i}^{n} a_{4 i} \Delta \log P_{t-1}^{f} \\
& +\sum_{i}^{n} a_{5 i} \Delta \log E X_{t-1}+\sum_{i}^{n} a_{6 i} \Delta \log g_{t-1}+a_{7} D_{1987}+a_{8} D_{1999}+B_{1} \log M_{t-i}^{s} \\
& -B_{2} \log Y_{t-i}+B_{3} \log e_{t-i}+B_{4} \log P_{t-1}^{f}+B_{5} \log E X_{t-1}+B_{6} \log g_{t-1}+B_{7} D_{1987} \\
& +B_{8} D_{1999}+e_{t}
\end{aligned}
$$

The first part of the equation with $a_{1}, a_{2} . a_{3}, a_{4}, a_{5}, a_{6}, a_{7}$, and $a_{8}$ represents the short-run dynamics of the model whereas the parameters $B_{1}, B_{2} . B_{3}, B_{4}, B_{5}, B_{6}, B_{7}$, and $B_{8}$ represents the long-run dynamic coefficients of the underlying ARDL model.

The ARDL model requires two steps for estimating long run relationships. The first step is to investigate the existence of long relationship among all variables in the equation under estimating. This can be done by using the F-test. Once a long-run co-integration relationship is found to exist the second step is to estimate the long-run and short-run elasticities. The empirical results for our model are now presented

The first step is to test for presence of the long-run relationship through the bounds testing approach. The result of the ARDL bounds test with regard to Libya is reported in Table 4. This result implies that the computed F-statistic is greater than the upper bound critical value. Hence, we have strong evidence to reject the null hypothesis of no co-integration at 5 percent significance level. It shows that the variables of interest are bound together in a long run relationship.

Table 4: F-test for a Co-integration Relationship

\begin{tabular}{|c|c|c|c|c|c|}
\hline Equation & $\begin{array}{c}95 \% \\
\text { Lower bound }\end{array}$ & $\begin{array}{c}95 \% \\
\text { Upper } \\
\text { bound }\end{array}$ & $\begin{array}{c}90 \% \\
\text { Lower } \\
\text { bound }\end{array}$ & Upper bound & $\begin{array}{c}\text { The } \\
\text { computed F- } \\
\text { statistic }\end{array}$ \\
\hline$F\left(p / \boldsymbol{M}^{\boldsymbol{S}}, Y, e, \boldsymbol{p}^{\boldsymbol{f}}, E, g, \boldsymbol{D}_{\mathbf{1 9 8 7}}, \boldsymbol{D}_{\mathbf{1 9 9 9}}\right)$ & 2.6039 & 3.7458 & 2.2897 & 3.3826 & 9.9442 \\
\hline
\end{tabular}

Following establishment of the existence of co-integration, we estimate the long run coefficients of our ARDL model. The empirical results in Table 5 reveal that in long-run the narrow money supply, expected inflation rate, imported inflation, exchange rate and output gap have a positive effect upon rate of inflation in Libya, and are statistically significant at $5 \%, 1 \%, 1 \%, 1 \%$, and $10 \%$ level respectively. Specifically, the empirical results show that one percent increase in money supply leads to 0.38 percent a rise in inflation and one percent increase in expected inflation result in an increase 0.02 percent in rate of inflation. Similarly, one percent increase in imported inflation bring about an increase in rate of inflation by 0.29 percent and one percent increase in exchange rate leads to 0.18 point increase in the inflation rate. On contrast, a 1 percent increase in real income will result in a decrease in the rate of inflation by 0.42 percent.

It must also be mentioned that the structural break for 1987 has had a negative effect on inflation increasing, the coefficient of which, according to the results in Table 5, has the negative value of 0.08 , which is statistically significant at 10 percent level. The structural change of 1987 is consistent with the introduction of Law No.15 in the early 1980s, when wages were frozen. Similarly, the structural change of 1999 is also significant. The dummy variable for 1999 has a positive sign indicating that it has a positive long-run impact upon the rate of inflation in the Libyan economy. The structural change for 1999 coincided with the depreciation of the official exchange rate.

Table 5: Estimated Long -run Coefficients using the ARDL Approach

\begin{tabular}{|l|c|c|c|c|}
\hline Regressor & Coefficient & Standard Error & T-Ratio & {$[$ Prob] } \\
\hline $\mathrm{M}^{\mathrm{S}}$ & $0.38062^{* *}$ & 0.13718 & 2.7746 & {$[.011]$} \\
\hline $\mathrm{Y}$ & $-0.42470^{* * *}$ & 0.21329 & -1.9912 & {$[.058]$} \\
\hline
\end{tabular}




\begin{tabular}{|l|c|c|c|c|}
\hline $\mathrm{e}$ & $0.02147^{*}$ & 0.00752 & 2.8550 & {$[.009]$} \\
\hline $\mathrm{p}^{\mathrm{f}}$ & $0.29816^{*}$ & 0.06715 & 4.402 & {$[.000]$} \\
\hline $\mathrm{EX}$ & $0.18390^{*}$ & 0.04022 & 1.8734 & {$[.000]$} \\
\hline $\mathrm{g}$ & $0.09723^{* * *}$ & 0.05190 & -2.0158 & {$[.073]$} \\
\hline $\mathrm{D}_{1987}$ & $-0.08305^{* * *}$ & 0.04120 & 3.3221 & {$[.055]$} \\
\hline $\mathrm{D}_{1999}$ & $0.17793^{*}$ & 0.05356 & 2.0916 & {$[.002]$} \\
\hline $\mathrm{INPT}$ & $0.22847^{* *}$ & 0.10923 & -2.2491 & {$[.047]$} \\
\hline Trend & $-0.56471^{* *}$ & 0.25108 & {$[.034]$} \\
\hline
\end{tabular}

Note: 1 .The results obtained by using the Microfit 5 package.

2. Dependent variable is $p$ and ARDL model $(1,1,1,0,0,0$, and 0$)$ is selected based on Schwartz Bayesian Criteria.

3. The asterisks $*, * *$ and $* * *$ denotes statistically significant at 1-percent, 5-percent and 10-percent level respectively.

After estimating the long-run coefficients, we obtain the error correction representation of the ARDL model. Table 6 reports the short-run coefficients estimates obtained from the ECM version of the ARDL model. The result for the error correction term for rate of inflation indicates that the estimated coefficient of the ECM (0.45 ) has the correct sign and is statistically significant at the one percent level and is moderately large, showing a strong and significant tendency for inflation rate to return back to long-run equilibrium when shocks occurred in the short-run. The result specifically states that deviation from the long-term rate of inflation is corrected by 45 percent in the next period. Furthermore, significant error correction confirms the existence of a stable longrun relationship among the significant explanatory variables and the rate of inflation.

Table 6: Short-run Error Correction Model (ECM)

\begin{tabular}{|l|c|c|c|c|}
\hline \multicolumn{1}{|c|}{ Regressor } & Coefficient & Standard Error & T-Ratio & {$[$ Prob] } \\
\hline $\mathrm{dM}^{\mathrm{S}}$ & $0.25587^{* *}$ & 0.09960 & 2.5689 & {$[.011]$} \\
\hline $\mathrm{dY}$ & $-0.31052^{* * *}$ & 0.15699 & -1.9780 & {$[.060]$} \\
\hline $\mathrm{de}$ & $0.00963^{* *}$ & 0.00379 & 2.5409 & {$[.021]$} \\
\hline $\mathrm{dp}^{\mathrm{f}}$ & $0.13375^{*}$ & 0.02622 & 5.1011 & {$[.000]$} \\
\hline $\mathrm{dEX}$ & $0.08250^{*}$ & 0.02311 & 3.5699 & {$[.001]$} \\
\hline $\mathrm{dg}$ & $0.04362^{* * *}$ & 0.02491 & -1.6694 & {$[.094]$} \\
\hline $\mathrm{dD}$ & -0.03726 & 0.02232 & 2.8774 & {$[.111]$} \\
\hline $\mathrm{dD}_{1999}$ & $0.07982^{*}$ & 0.02774 & -2.0476 & {$[.009]$} \\
\hline $\mathrm{dTr}_{\mathrm{N}}$ & $-0.25333^{* * *}$ & 0.12372 & -3.9664 & {$[.056]$} \\
\hline $\mathrm{ECM}(-1)$ & $-0.44860^{*}$ & 0.11310 & & {$[.001]$} \\
\hline $\mathrm{R}^{2}=80173$ & $\mathrm{R}^{\backslash 2}=71676$ & $\mathrm{DW}=2.0116$ & & \\
\hline
\end{tabular}

The asterisks *** and $* * *$ denotes statistically significant at 1-percent, 5-percent and 10-percent level respectively.

To ascertain the goodness of fit of the ARDL model, the stability tests are conducted. The structure stability of the long-run and short-run relationships of the ARDL model for the entire period is examined by the cumulative sum (CUSUM) and the cumulative sum of squares (CUSUMQ) of the recursive residual test which provided by Brown et al (1975). These two tests are presented in Fig 1. The pair of straight lines in each figure indicates the 5 percent significant level and if the plotted CUSUM and CUSUMQ graphs remain inside the straight lines the null hypothesis of correct specification of the model can be accepted. Otherwise, the null hypothesis is rejected and it can be concluded the regression equation is miss-specified. The two figures reveal that the plots of CUSUM and CUSUMSQ stay within the lines, and therefore, this clearly indicate the absence of any instability of coefficients during the investigated period.

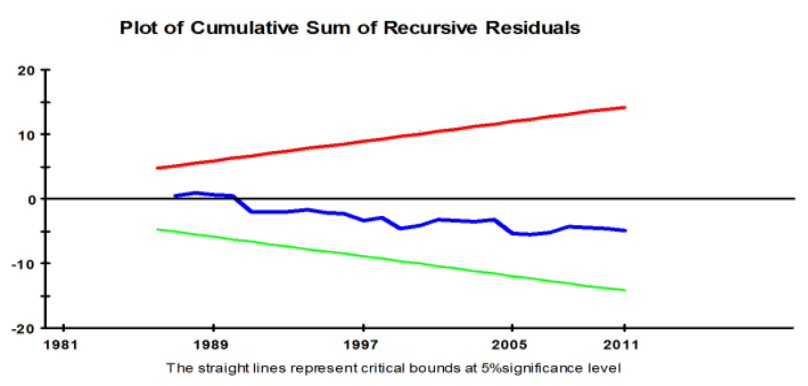


Plot of Cumulative Sum of Squares of Recursive Residuals

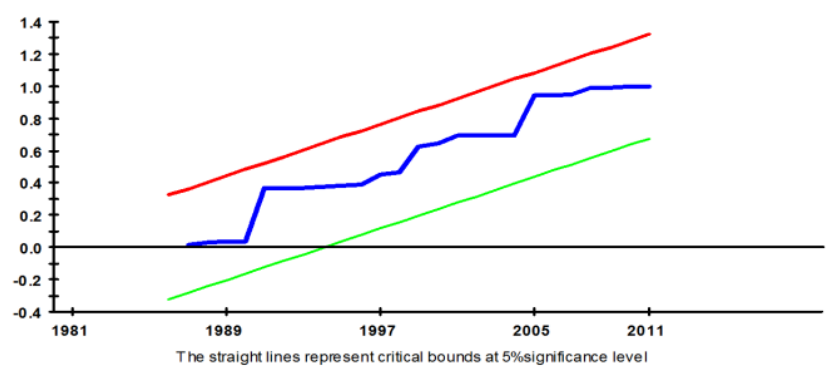

Figure 1: Plots of CUSUM and CUSUMQ Statistics for Coefficients Stability Tests

\section{Conclusion}

The empirical results confirm the existence of a co-integration relationship among the variables under study. Based on the results in both the long and short-run, money supply, imported inflation, and real income have the most significant impact on the inflation rate in the Libyan economy. After the above variables, other variables such as exchange rate, output gap, and inflation expectation are the effective factors in inflation rise, respectively. Moreover, the error correction term $(-0.45)$ is found to be negative and statistically significant showing a strong and significant tendency for inflation rate to return back to long-run equilibrium when shocks occurred in the short-run.

Regarding the appropriate economic policies, aiming to minimize the adverse impact of both domestic and foreign factors on the inflation rate in the Libyan economy, the major outcomes of this study suggest that a development oriented policy in form of increased government investment on various sectors of the economy, in particular oil and gas sector results in an improvement of economic growth which will in turn reduce to inflation rate. It also suggests that policy of imports substitution not only contributes to reduce the Libyan economy' dependence on imports, but also protect itself against changes in its prices, and therefore, leads to reduce impact of foreign factor on domestic inflation. Moreover, inflation can be also cured by a sufficiently tight monetary policy through instituting appropriate mechanisms to sterilize foreign exchange injections into the Libyan economy.

\section{References}

[1] Makinen.G, Inflation: Causes, Costs, and Current Status, Report for Congress RL30344, 2003.

[2] Parkin. M, Economics (United States, Addison Wesley, 2000).

[3] Gupta.G, Macroeconomics: Theory and Applications ( New Delhi, Tata Mcgraw, 2008).

[4] Moulton.B, Bias in the consumer price index: what is the evidence? , the journal of economic perspectives, $10(4), 1996$.

[5] World Bank, Socialist People's Libyan Arab Jamahiriya Country Economic Report, Social and Economic Development Group Middle East and North Africa Region, Report, 30295-LY,2006.

[6] Krim.S, A comparative study of factors that influence foreign direct investments in Libya, Malaysia, and Emirates, University Tun Abdul Razak, 2009.

[7] Alomar. H, Determinants of inflation in Kuwait, Journal of Economic and Administrative Sciences, $23(2), 2007$.

[8] Barnichon.R, and Peiris.S, Sources of inflation in Sub-Saharan Africa. International Monetary Fund, working paper WP/07/32, 2007.

[9] Kandil. M , and Morsy. H, Determinants of Inflation in GCC. International Momentary Fund, working paper WP/09/82, 2009.

[10] Tang.C, Is inflation always a monetary phenomenon in Malaysia?, MPRA Paper (19778), 2010.

[11] Patnaik A, Study of inflation in India: A co-integrated vector auto regression approach, Journal of Quantitative Economics, 8(1), 2010.

[12] Dwyer. A, K. Lam, and A. Gurney, Inflation and the output gap in the UK. Treasury economic working paper (6), 2010.

[13] Oladipo. S, and Akinbobola. T, Budget deficit and inflation in Nigeria: A causal relationship, Journal of Emerging Trends in Economics and Management Sciences, 2 (1), 2011.

[14] Dizaji. S, Analysis of domestic price and inflation determinants in Iran (as a developing oil-export based economy), International Institute of Social Studies, Working Paper (530), 2011.

[15] Agayev. S, Exchange Rate, Wages, and Money; What Explains Inflation in CIS Countries: Panel Causality and Panel Fixed Effects Analysis, Middle Eastern Finance and Economics, ISSN: 1450-2889 Issue 9, 2011.

[16] Kinda. T, Modeling Inflation in Chad, International Monetary Fund, Working Paper, WP/11/57, 2011.

[17] International Monetary Fund (IMF), International Financial Statistics, yearbooks, 2005, 2008 , and 2011.

[18] Dickey. D, and Fuller. W, Distribution of the estimators for autoregressive time series with a unit root, Journal of the American Statistical Association, 74(366), 1979.

[19] Dickey. D, and Fuller. W, Likelihood ratio statistics for autoregressive time series with a unit root, Econometrica (pre-1986),49(4), 1981.

[20] Philips. P, and Perron. P, Testing for a unit root in time series regression, Biometrika, 75(2), 1988.

[21 ] Lee.J, and Strazicich.M , Minimum Lagrange Multiplier Unit Root Test with Two Structural Breaks, The Review of economics and statistics, 85(4),2003. 
[22] Sen, A, On unit-root tests when the alternative is a trend-break stationary process, Journal of Business and Economic Statistics, 21(1), 2003.

[23] Pesaran .M, Shin. H, and Smith. J, Bounds testing approaches to the analysis of level relationships, Journal of Applied Econometrics, 16: 289-326, 2001.

[24] DaCosta. D, and Greenidge .K, Determinants of Inflation in Selected Caribbean Countries, business, finance \& economics in emerging economies, 4 (2), 2009.

[25] Perron. P, The great crash, the oil price shock, and the unit root hypothesis, Econometrica, 57, 1989.

[26] Brown. R, Durbin. J, and Evans. M, Techniques for testing the constancy of regression relations over Time, Journal of the Royal Statistical Society, 37, 1975. 